\title{
The antecedents of herbal product actual purchase in Malaysia
}

\author{
Sarina Ismail ${ }^{\mathrm{a}^{*}}$ and Sany Sanuri Mohd Mokhtar ${ }^{\mathrm{b}}$
}

${ }^{a}$ OthmanYeop Abdullah Graduate School of Business, Universiti Utara Malaysia, Sintok, Malaysia ${ }^{b}$ SchoolOf Business Management, Universiti Utara Malaysia, Sintok, Malaysia

\begin{tabular}{l}
\hline C H R O N I C L E \\
\hline Article history: \\
Received March 18, 2015 \\
Received in revised format 28 \\
March 2015 \\
Accepted 29 May 2015 \\
Available online \\
May 30 2015 \\
\hline Keywords: \\
Intention \\
Attitude \\
Social influence \\
Product safety \\
Cultural belief \\
Actual purchase \\
\hline
\end{tabular}

\begin{abstract}
A B S T R A C T
This study is meant to examine the relationships of several antecedents of actual purchase of herbal product in Malaysia. Actual purchase is considered to have a vital link to a business success. The study identified eight antecedents of consumer actual purchase such as intention, attitude, social influence, product safety and culture belief. A total of 473 respondents (about $82 \%$ ) completed and returned the questionnaire. A seven point Likert scale was used to measure responses. The data were analyzed using Partial Least Squares (PLS) path modeling. The path coefficient results supported the direct influence of intention, attitude, social influence and product safety on actual buying. Moreover, the findings reveal that attitude, social influence, product safety, and culture belief also influenced buying intention.
\end{abstract}

\section{Introduction}

The global demand on herbal products has increased due to the worldwide awareness and preferred trend for natural alternatives to synthetic products (Ab Karim et al., 2011; Abdullah et al., 2010; Jamal, 2006). Herbal products have also been associated with health care solutions in treating and preventing various diseases. For instance, it has been reported that herbal products are used to relieve symptoms related with HIV/AIDS (WHO, 2011). There are several factors that contribute to these phenomena's (Raghavendra, 2009; Saokaew, 2011) namely; inefficient conventional medicine that results of side effects and other problems, accessibility of conventional medicine, perception of the herbal product i.e. harmless, desire for self-medication, and cheaper costs. Previous studies on herbal products was carried out by previous researchers are associated with the use of herbal therapy (Ritho et al., 2002), the frequency of using herbal supplements (Al-Naggar et al., 2011; Kelly et al., 2005; Tangkiatkumjai et al., 2013), the use of herbal medicine (CAM) (AlBraik et al., 2008; Arcury et al., 2007; Aziz et al., 2009), the use of herbal products (Abdullah et al.,, 2010; Brown et al.,2009), herbal drink (Chelliah et al., 2011; Hassali et al., 2009), the purchase of herbal cosmetics (Thanisorn et al., 2012), and intention to use of functional food (Rezai et al., 2012). Hence, past research also exposes that there is a lack of studies that examine the influence of actual purchase of herbal products in Malaysia.

\footnotetext{
* Corresponding author.

E-mail address: isarina4@gmail.com (S. Ismail) 


\section{Literature Review}

Actual purchase has long been of interest to researchers. This is because knowledge regarding actual purchase will help researchers understand the customers' needs. Thus, the data obtained from the actual purchase can help to identify the marketing strategy (Kim et al., 2011), customer satisfaction, and to ensure the continuity of the business (Carneiro et al., 2005; Ibrahim et al., 2008; Paul et al., 2012). Certain studies found that actual purchase was complex and vary by segment (Chiang et al., 2010; Shafiq et al., 2011). Ajzen (1985) defined actual purchase behavior as an "individual's readiness and willingness to purchase a certain product or service”. Past studies have identified several predictors of actual behavior: intention (Akehurst et al., 2012; Al-Ekam, 2013; Facchinetti et al., 2012; Rezai et al., 2011) and perceived behavior control (Ahmed Al-Qasa, 2013; Maldonado et al., 2011; Zia-ur-Rehman et al., 2013), and subjective norm (Albayrak et al., 2013; Pomsanam et al., 2014; Son et al., 2013).

\subsection{Theoretical Underpinning of Study}

The theory of planned behavior (TPB) is an extension of the theory of reasoned action (TRA) due to the limitations of TRA (Ajzen \& Fishbein, 1980; Fishbein \& Ajzen, 1975). TPB is created in order to study the behavior of individuals who do not have control over their behavior (Ajzen, 1991, 2002). Fishbein and Ajzen (1975) described intention as a determinant of behavior, where intention is influenced by three constructs: attitude toward the behavior, subjective norms, and behavioral control. This theory suggests that the stronger the individuals desire to engage with the behavior, and then more likely he will do it (Armitage \& Conner, 1999). Meanwhile attitude towards behavior refer to favorable or unfavorable assessment of the individuals, while the subjective norm refers to the confidence of individuals in compliance what other people think whether he should or should not do. Lastly perceived behavior control indicates whether users can use a product or find difficulties in using it (Ajzen, 1991).

\subsection{Intention and Actual Purchase}

Purchase intention plays a fundamental role as essential to the actual purchase and also an important basis for the predicted actual purchasing behavior (Gomes \& Neves, 2011). Besides, intention has been studied extensively by researchers in the field of marketing and found that intention affected the behavior and actual purchase. In studies related to the use of herbal medicine and product by Gupchup et al. (2006) found that the intention to use herbal medicine is positively affected the actual usage. Whereas studies by Rezai et al. (2013), Ismail and Mohd Mokhtar (2015) in Malaysia in relation to herbal product found that intention affects the actual purchase significantly.

\subsection{Attitude and Actual Purchase}

Past research also showed that attitude plays a very important role in ensuring a positive or negative assessment of the behavior and the actual purchase (O’Connor \& White, 2009). There are some studies conducted which found that attitudes can influence behavior directly and it is considered as a better predator then intention (Al-Majali, 2011; Hashjin et al., 2014). A study related to herbal products carried out by Marinac et al. (2007) found that the attitude has influenced the use of herbal products. While the study by Thongruang (2008) relating to the behavior of the use of herbal medicine in Thailand found that attitude affected actual usage. In addition, other studies that have been conducted by Brown et al. (2009) in the United States on 139 respondents also indicated that attitudes play an important role in influencing the use of herbal products. Followed by a study of Mitha et al. (2013) found that attitude also affected consumers' actual purchase of herbal products in Malaysia.

\subsection{Social Influence and Actual Purchase}

Social influence is often associated with the way in which others give the impression to the trust, a person's feelings and behaviors (Chow et al., 2012; Mason et al., 2007) and has been studied by researchers such as Conner et al. (2001) and Pawlak et al.(2007). Other studies, in Malaysia found that 
social influence greatly affects actual purchase of products (Mohamed Omar et al., 2012; Mohd Zahran et al., 2012). While studies by Aertsens et al. (2009) in Belgium found that social influence also greatly influenced actual behavior. Meanwhile, the study of Alkhateeb et al. (2006) examined the relationship between social influence and actual behavior and found that the social influence plays a vital role in purchasing herbal product.

\subsection{Product Safety and Actual Purchase}

The issue related to the safety of herbal product is increasing; this is because the herbs may cause toxicity and serious adverse. In order to protect the safety of customers, the quality of herbal products need to be determined (Fu et al., 2009). According to Grunert (2005), product safety is the customers' belief on how safe is the product. It is also associated with customers' concerns over the safety of the product in the manufacturing process (Michaelidou \& Hassan, 2008). Product safety plays an important role in defining whether a product is safe to be purchased or used (Chaudhuri \& Holbrook, 2001; Lodorfos et al., 2006). Past research concerning the relationship between product safety and actual purchase consumption was conducted by De Silva and Sandika (2011) in Sri Langka found that product safety affected the actual purchase.

\subsection{Attitude and Intention}

The relationship between attitudes and purchase intentions has been discussed in the past research in the field of marketing. According to TPB, the more individual's positive beliefs against the object, the more positive attitude of individuals towards the object (Fishbein \& Ajzen, 1975). Previous studies examined the relationship between attitude and intention and found that it was positive (Chen \& $\mathrm{Li}$, 2007; Mukhtar \& Butt, 2012; Tarkiainen \& Sundqvist, 2005).Other study related nutraceuticals product by Tsai et al. (2010) found that attitudes also influence intention significantly.

\subsection{Social Influence and Intention}

Past research that has been carried out in studies relating to the use of herbal medicine was conducted by Gupchup et al. (2006) found that social influence affected the intention to use the product. Others studies that examined the relationship between social influence and intentions also confirmed the effect of social influence toward intention (Al-Shafi \& Weerakkody, 2010; Esmaili et al., 2011; Maldonado et al., 2011; Rimal et al., 2006; Sok Foon \& Chan Yin Fah, 2011).

\subsection{Product Safety and Intention}

Previous studies related to the safety of products has examined the relationship between safe products and purchase intentions by Michaelidou and Hassan (2008) in the United Kindom, Pino et al. (2012) in Italy and followed by studies by Ahmad and Juhdi (2008b), Shaharudin et al. (2010b) and Chiew et al. (2014) in Malaysia found that product safety is found to play a very important role the influence on purchase intention.

\subsection{Cultural Belief and Intention}

Cultural belief is a trust that affects perception and purchasing behavior and it was also found to be very important in understanding the needs and wants of consumers (Dindyal, 2003; Dixit, 2001). Studies by Moon et al. (2008) in New Zealand found that individualistic cultural beliefs had more effect on purchase intention as compared to the collective culture. While the studies that have been conducted by Esmail Mohammed Al-Ekam, et al. (2012) in Yemen found that cultural beliefs affected purchase intention significantly. Followed by a study which has been carried out by Al-Qasa et al. (2013) in Yemen also found that cultural beliefs affected intention significantly. 


\section{Sample and procedures}

The data in this study was collected through mall intercept survey at six various states in Malaysia. The survey included measures of actual purchase, intention, attitude, social influence, product safety, and cultural belief. A total of 576 questionnaires were distributed, but only 473 were returned representing a total of $82 \%$ response rate. Out of 473 respondents, $64.3 \%$ is dominated by female, while male accounted for $35.7 \%$ of total response. The distribution of respondents was dominated by Malays (55.8\%), followed by Chinese (28.8\%), Indian (15.9\%), and others had .2\%.

\section{Measures}

The measurement scales of constructs were taken from past studies. In particular, actual purchase is measured using four items adapted from two sources (Chaudhuri \& Holbrook, 2001; Hassan, 2011b). In assessing the purchase intention, this study used four items adapted from three sources (Chaudhuri \& Holbrook, 2001; Conner et al., 2001; Jaafar et al., 2012). Attitude is measured using five item adapted from two sources (Hassan, 2011a; Pawlak et al., 2007). Social influence is measured using five item taken from three sources (Furnham \& Lovett, 2001; Klepser et al., 2000; Pawlak et al., 2007). Meanwhile, product safety construct is measured using four items adapted from three sources (de Jonge et al. 2007; Michaelidou \& Hassan, 2008; Rimal, 2005). Lastly, the cultural belief construct is measured by using four item taken from one source (Hassan, 2011a). This study used seven point Likert scale ranging $1=$ strongly disagree to $7=$ =strongly agree. Furthermore, the use of the above source scale is justified as it has been found to be reliable and reached acceptable alpha coefficients of more than 0.70 (Nunnally, 1978).

\section{Result}

Before proceeding to the regression analysis, several assumptions need to be met: i) missing values ii) assumption of outliers, iii) normality assumption, and iv) Multicollinearity assumption (Hair et al. 2010; Tabachnick \& Fidell, 2007). In particular, all data were screened for missing values using SPSS. No missing data was found. Next, multivariate outliers were checked and thirty two items were detected as having outliers. All items in the dataset were screened to ensure that normality assumption was not violated.

\subsection{Descriptive Analysis}

Based on the results of the descriptive analysis, the average respondent are between the ages of eighteen to sixty seven years. The average income of respondents was from RM800 to RM12,000. From 473 in data analysis, it is shown that the majority of respondents were dominated by women that (64.3\%) as compared with another $37.7 \%$ men. From all the four ethnic groups in Malaysia, Malay respondents are $55.8 \%$, followed by the second largest ethnic group that is the Chinese (28.8\%). The third ethnic group Indian is $15.9 \%$. Most of the respondents are Muslim (54.8\%) followed by $18.2 \%$ Buddhism. 9.9\% Hindu and Christians $17.1 \%$. The findings of analysis also reported that the majority of the respondents are married (63\%) compared to those who have not been married 32.6\% and the remaining $4.4 \%$ are already divorced.

Descriptive analysis of results on 473 respondents found that 385 (81.4\%) are repeat purchasers and 88 (18.6\%) are a first-time purchasers. The analysis also found that $37.4 \%$ of the respondents have used herbal products between six to one year, while $27.7 \%$ has used from one year to two years. Followed by $23 \%$ of the respondents are those who use herbal products less than six months and only $11.8 \%$ are those who have been using for more than two years. Descriptive data pertaining to the purchase indicated that average 38.1\% of the respondents are those who buy between RM51-RM100 followed by $24.1 \%$ who had purchased between RM101-150. Moreover, $21.1 \%$ of the respondents had purchased less than 50 and the rest are the respondents who buy between RM151-RM200 at 9.5\%. Similarly, 3.8\% 
of the respondents bought between RM201-RM250, 1.7\% of the respondents had purchased more than RM301 and 1.3\% of the respondents had purchased between RM251-RM300.

\subsection{Measurement Model}

In order to ensure the construct validity, we followed a two-step modeling approach as suggested by Hair et al. (2014). At first, convergent validity and reliability were assessed, followed by the discriminant validity, then internal consistency reliability as shown in Table 1 and Table 2 respectively were conducted. As a rule of thumb, construct validity is ascertained if the loadings are greater than 0.7 , composite reliability is greater than 0.7 , average variance extracted is greater than 0.5 , and Cronbach's alpha is greater than 0.7 .

Table 1

Results of measurement model

\begin{tabular}{|c|c|c|c|c|c|}
\hline Latent Variable & Items & Loading & $\begin{array}{c}\text { Average variance } \\
\text { extracted }\end{array}$ & $\begin{array}{l}\text { Composite } \\
\text { Reliability } \\
\end{array}$ & $\begin{array}{c}\text { Cronbach's } \\
\text { Alpha } \\
\end{array}$ \\
\hline \multirow{4}{*}{ Actual Purchase } & BS56 & 0.831 & \multirow{4}{*}{0.712} & \multirow{4}{*}{0.908} & \multirow{4}{*}{0.865} \\
\hline & BS57 & 0.879 & & & \\
\hline & BS58 & 0.820 & & & \\
\hline & BS59 & 0.845 & & & \\
\hline \multirow{4}{*}{ Intention } & N54 & 0.811 & \multirow{4}{*}{0.554} & \multirow{4}{*}{0.830} & \multirow{4}{*}{0.725} \\
\hline & N55 & 0.849 & & & \\
\hline & N9 & 0.693 & & & \\
\hline & N6 & 0.599 & & & \\
\hline \multirow{5}{*}{ Attitude } & S40 & 0.821 & \multirow{5}{*}{0.720} & \multirow{5}{*}{0.928} & \multirow{5}{*}{0.903} \\
\hline & S41 & 0.844 & & & \\
\hline & S42 & 0.841 & & & \\
\hline & S43 & 0.875 & & & \\
\hline & S44 & 0.861 & & & \\
\hline \multirow{5}{*}{ Social Influence } & FL45 & 0.823 & \multirow{5}{*}{0.729} & \multirow{5}{*}{0.931} & \multirow{5}{*}{0.907} \\
\hline & FL46 & 0.865 & & & \\
\hline & FL47 & 0.886 & & & \\
\hline & FL48 & 0.860 & & & \\
\hline & FL49 & 0.834 & & & \\
\hline \multirow{4}{*}{ Product Safety } & KP50 & 0.847 & \multirow{4}{*}{0.837} & \multirow{4}{*}{0.953} & \multirow{4}{*}{0.935} \\
\hline & KP51 & 0.925 & & & \\
\hline & KP52 & 0.947 & & & \\
\hline & KP53 & 0.937 & & & \\
\hline \multirow{4}{*}{ Cultural Belief } & KB22 & 0.793 & \multirow{4}{*}{0.708} & \multirow{4}{*}{0.906} & \multirow{4}{*}{0.863} \\
\hline & KB23 & 0.861 & & & \\
\hline & KB24 & 0.889 & & & \\
\hline & KB25 & 0.820 & & & \\
\hline
\end{tabular}

We also conducted the discriminant validity following Fornell and Larcker(1981) recommendations. On the basis of their recommendations, the average variance shared between each construct and its measures should exceed the variance shared between the construct and other constructs (Fornell \& Larcker, 1981).

\section{Table 2}

Discriminant validity of constructs

\begin{tabular}{|c|c|c|c|c|c|c|}
\hline Latent variable & Actual Buying & Attitude & $\begin{array}{c}\text { Culture } \\
\text { Belief }\end{array}$ & Intention & Product Safety & Social Influence \\
\hline Actual Buying & 0.844 & & & & & \\
\hline Attitude & 0.720 & 0.849 & & & & \\
\hline Culture Belief & 0.100 & 0.176 & 0.841 & & & \\
\hline Intention & 0.692 & 0.693 & 0.238 & 0.744 & & \\
\hline Product Safety & -0.189 & -0.215 & 0.386 & -0.158 & 0.915 & \\
\hline Social Influence & 0.695 & 0.741 & 0.253 & 0.711 & -0.131 & 0.854 \\
\hline
\end{tabular}

Note: Diagonals (bold face) represent the square root of the average variance extracted while the other entries represent the correlations. 
As shown in Table 2, the correlations for each construct is less than the square root of the average variance extracted suggesting adequate discriminant validity of the constructs (Hair et al., 2010).

\subsection{Structural Model}

Following the measurement model next was the structural model. The results are presented in Table 3 and Fig. 1. The $\mathrm{R}^{2}$ values of 0.57 for intention and 0.61 for actual purchase which suggest that the modeled variables can explain $61 \%$ of variance in in actual purchase.

Table 3

Path coefficients and hypothesis testing

\begin{tabular}{cccccc}
\hline Hypothesis & Relation & Beta & Standard Error & T Statistics & Finding \\
\hline H1 & I $\rightarrow$ AP & 0.281 & 0.051 & $5.514^{* * *}$ & Supported \\
H2 & A $\rightarrow$ AP & 0.340 & 0.053 & $6.474^{* * *}$ & Supported \\
H3 & SI $\rightarrow$ AP & 0.238 & 0.047 & $5.026^{* * *}$ & Supported \\
H4 & PS $\rightarrow$ AP & -0.040 & 0.028 & 1.427 & Not Supported \\
H5 & A $\rightarrow$ I & 0.353 & 0.044 & $7.939^{* * *}$ & Supported \\
H6 & SI $\rightarrow$ I & 0.418 & 0.041 & $10.136^{* * *}$ & Supported \\
H7 & PS $\rightarrow$ I & -0.064 & 0.032 & $2.031^{* *}$ & Supported \\
H8 & CB $\rightarrow$ I & 0.095 & 0.036 & $2.641^{* * *}$ & Supported \\
\hline
\end{tabular}

Actual Buying $\left(\mathrm{R}^{2}\right)=61 \%$

Note: $* * * \mathrm{p}<0.01,{ }^{* *} \mathrm{p}<0.05$
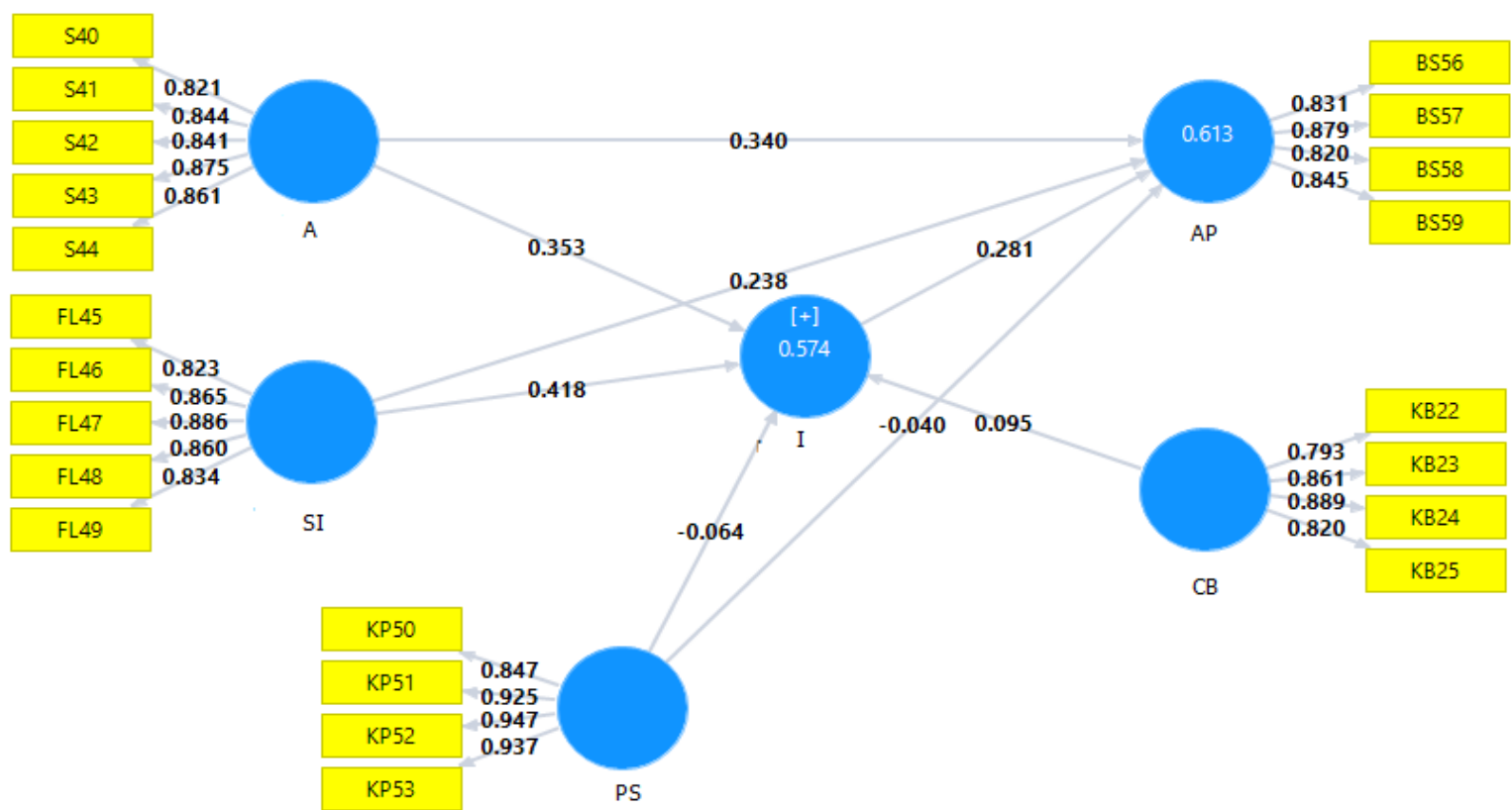

Fig. 1. Structural Model Analysis output

\section{Discussion}

This study investigated the influence of the antecedents such as intention, attitude, social influence, product safety, and cultural belief. The result showed that buying intention, attitude, and social influence are positively related to actual buying. This finding is consistent with the result of previous research (e.g. Gopi \& Ramayah, 2007; Pawlak et al., 2007). The result in this study also indicated the attitude, social influence, product safety and cultural belief is found to be related to intention (e.g. Pino et al., 2012; Soyez et al., 2012). The finding of this study also revealed that product safety was not a significant predictor of actual purchase. This finding shows that even though the consumers are concerned about the safety of the product; but there is still other factors that influence the actual 
purchase such as social influence and culture belief. Meanwhile, this study also confirms that attitude and social influence are good predator toward actual purchase and this finding confirms the previous studies which were done by Al-Majali (2011) and Hashjin et al. (2014).

\section{References}

Ab Karim, M. ., Nasouddin, S. ., Othman, M., Mohd Adzahan, N., \& Hussin, S. (2011). Consumers ’ knowledge and perception towards Melicope ptelefolia ( Daun Tenggek Burung ): A preliminary qualitative study. International Food Research Journal, 18(4), 1481-1488.

Abdullah, N., \& Salleh, S. (2010). Factors Related to the Use of Herbal Products and Derivatives from Consumers ' Perspective in Kota Kinabalu, Sabah : An Initial Study. Sosiohumanika, 3(1), 143-154.

Aertsens, J., Verbeke, W., Mondelaers, K., \& Van Huylenbroeck, G. (2009). Personal Determinants of Organic Food Consumption : A Review. British Food Journal, 111(10), 1140-1147.

Ahmed Al-Qasa, K. M. (2013). Factors Determining The Purchase Intention Of Bank Services in The Republic of Yamen. Universiti Utara Malaysia.

Ajzen, I. (1985). From Intention to Actions: A Theory of Planned Behaviour. In Springer Series ini Sosial Psychology (pp. 11-39). Verlag Berlin Heidelberg: Springer Berlin Heidelberg.

Ajzen, I. (1991). The Theory of Planned Behavior. Organizational Behavior and Human Decision Processes, 50(2), 179-211. doi:10.1016/0749-5978(91)90020-T

Ajzen, I. (2002). Perceived Behavioral Control , Self-Efficacy, Locus of Control, and the Theory of Planned Behavior. Journal of Applied Social Psychology, 32(4), 665-683.

Ajzen, I., \& Fishbein, M. (1980). Understanding attituted and predicting social behavior. Englewood Cliffs,NJ: Prentice Hall.

Akehurst, G., Afonso, C., \& Gonçalves, H. M. (2012). Re-examining green purchase behaviour and the green consumer profile: new evidences. Management Decision, 50(5), 972-988. doi:10.1108/00251741211227726

Albayrak, T., Aksoy, S., \& Caber, M. (2013). The effect of environmental concern and scepticism on green purchase behaviour. Marketing Intelligence \& Planning, 31(1), 27-39. doi:10.1108/02634501311292902

AlBraik, F. A., Rutter, P., \& Brown, D. (2008). A cross-sectional Survey Of Herbal Remedy Taking by United Arab Emirate (UAE) Citizens in Abu Dhabi. Pharmacoepidemiology and Drug Safety, 17, 725-732. doi:10.1002/pds

Al-Ekam, J. M. E. (2013). Actual Purchase Behavior of Local Brand Antecedents in Yemen: The Mediating Effect of Purchase Intention. Universiti Utara Malaysia.

Alkhateeb, F. M., Doucette, W. R., \& Ganther-Urmie, J. M. (2006). Influences on Consumer Spending For Herbal Products. Research in Social \& Administrative Pharmacy, 2, 254-65. doi:10.1016/j.sapharm.2006.03.001

Al-Majali, M. M. (2011). The Antecedents of Internet Banking Services Adoption in Jordan Using Decomposed Theory of Planned Behaviour.

Al-Naggar, R. A., \& Chen, R. (2011). Prevalence of Vitamin-Mineral Supplements Use and Associated Actors Among Young Malaysians. Asian Pacific Journal of Cancer Prevention, 12, 1023-1029. Retrieved from http://www.ncbi.nlm.nih.gov/pubmed/21790245

Al-Shafi, S., \& Weerakkody, V. (2010). Factors Affecting E-Government Adoption in The State of Qatar. In European and Mediterranean on Informaton Systems (Vol. April 12-1, pp. 1-23). Retrieved from http://bura.brunel.ac.uk/handle/2438/4395

Arcury, T. A., Grzywacz, J. G., Bell, R. A., Neiberg, R. H., Lang, W., \& Quandt, S. A. (2007). Herbal Remedy Use As Health Self-Management Among Older Adults. The Journals of Gerontology., 62B(2), S142-S149. Retrieved from http://www.ncbi.nlm.nih.gov/pubmed/17379684

Armitage, C. J., \& Conner, M. (1999). The Theory of Planned Behaviour: Assessment of Predictive Validity and 'Perceived Control. British Journal of Social Psychology, 38(1), 35-54. doi:10.1348/014466699164022

Aziz, Z., \& Tey, N. P. (2009). Herbal medicines: prevalence and predictors of use among Malaysian adults. Complementary Therapies in Medicine, 17, 44-50. doi:10.1016/j.ctim.2008.04.008

Brown, B. S., Emmett, D., \& Chandra, A. (2009). Attitudes and Behavior of African-Americans Regarding the Consumption of Herbal Products-An Exploratory Study. Journal of Hospital Marketing \& Public Relations, 19(1), 40-51. doi:10.1080/15390940802581655

Carneiro, J. D. D. S. J. C. S., Minim, V. P. R., Deliza, R., Silva, C. H. O., \& Leão, F. P. (2005). Labelling effects on consumer intention to purchase for soybean oil. Food Quality and Preference, 16(3), 275-282. doi:10.1016/j.foodqual.2004.05.004 
Chaudhuri, A., \& Holbrook, M. B. (2001). The Chain of Effects from Brand Trust and Brand Affect to Brand Performance : The Role of Brand Loyalty. Journal of Marketing, 65(2).

Chelliah, S., \& Chin, K. K. (2011). A Study of the Relationship Between Marketing Mix and Customer Retention for Herbal Coffee in Malaysia. In 2nd International Conference on Business and Economic Research (2nd ICBER 2011) Proceeding (pp. 1541-1553).

Chen, M.-F., \& Li, H.-L. (2007). The Consumer's Attitude Toward Genetically Modified Foods in Taiwan. Food Quality and Preference, 18, 662-674. doi:10.1016/j.foodqual.2006.10.002

Chiang, D.-A., Wang, Y.-H., \& Chen, S.-P. (2010). Analysis on repeat-buying patterns. Knowledge-Based Systems, 23(8), 757-768. doi:10.1016/j.knosys.2010.04.012

Chow, M. M., Chen, L. H., Yeow, J.-A., \& Wong, P. W. (2012). Conceptual Paper: Factors Affecting the Demand of Smartphone among Young Adult. Social Science Economics \& Art, 2(2), 44-49.

Conner, M., Kirk, S. F., Cade, J. E., \& Barrett, J. H. (2001). Why do women use dietary supplements? The use of the theory of planned behaviour to explore beliefs about their use. Social Science \& Medicine, 52(4), 62133. Retrieved from http://www.ncbi.nlm.nih.gov/pubmed/11206658

De Jonge, J., van Trijp, H., Jan Renes, R., \& Frewer, L. (2007). Understanding Consumer Confidence in the Safety of Food: Its Two-Dimensional Structure and Determinants. Risk Analysis, 27(3), 729-740. doi:10.1111/j.1539-6924.2007.00917.x

De Silva, P. H. G. J., \& Sandika, A. L. (2011). Quality Standard Labeling Information on Meat Packs Demanded by Consumers and Relationships with Purchasing Motives. The Journal of Agricultural Science.

Esmaili, E., Desa, M. I., Moradi, H., \& Hemmati, A. (2011). The Role of Trust and Other Behavioral Intention Determinants on Intention toward Using Internet Banking. International Journal of Innovation, Management and Technology, 2(1), 95-100. Retrieved from http://www.ijimt.org/papers/111-E00102.pdf

Facchinetti, F., Pedrielli, G., Benoni, G., Joppi, M., Verlato, G., Dante, G., ... Cuzzolin, L. (2012). Herbal Supplements in Pregnancy: Unexpected Results From a Multicentre Study. Human Reproduction, 27(11), 3161-3167. doi:10.1093/humrep/des303

Fishbein, M., \& Ajzen, I. (1975). Belief, Attitude, Intention and Behaviour : The Introduction to Theory and Research. Addison-Wesley Publushing Company, Inc.

Fornell, C., \& Larcker, D. F. (1981). Evaluating Structural Equation Models with Unobservable Variable and Measuarement Error. Journal of Marketing Research, 18(1), 39-50.

Fu, P. P., Chiang, H.-M., Xia, Q., Chen, T., Chen, B. H., Yin, J.-J., ... Yu, H. (2009). Quality Assurance and Safety of Herbal Dietary Supplements. Journal of Enviromental Science and Health, 27(2), 91-119. doi:10.1080/10590500902885676

Furnham, A., \& Lovett, J. (2001). Predicting the Use of Complementary Medicine : A Test of the Theories of Reasoned Action and Planned Behavior. Journal of Applied Social Psychology, 31(12), 2588-2620.

Gomes, D., \& Neves, J. (2011). Organizational Attractiveness and Prospective Applicants' Intentions to Apply. Personnel Review, 40(6), 684-699. doi:10.1108/00483481111169634

Gopi, M., \& Ramayah, T. (2007). Applicability of theory of planned behavior in predicting intention to trade online Some evidence from a developing country. International Journal of Emerging Markets, 2(4), 348360. doi:10.1108/17468800710824509

Grunert, K. G. (2005). Food quality and safety: consumer perception and demand. European Review of Agricultural Economics, 32(3), 369-391. doi:10.1093/eurrag/jbi011

Gupchup, G. V., Abhyankar, U. L., Worley, M. M., Raisch, D. W., Marfatia, A. A., \& Namdar, R. (2006). Relationships between Hispanic ethnicity and attitudes and beliefs toward herbal medicine use among older adults. Research in Social \& Administrative Pharmacy, 2, 266-279. doi:10.1016/j.sapharm.2006.02.002

Hair, J. F. J., Black, W. C., Babin, B., \& Anderson, R. E. (2010). Multivariate Data Analysis A Global Perspective (Seventh Ed.). Prentice Hall.

Hair, J. F. J., Hult, G. T. M., Ringle, C. M., \& Sarstedt, M. (2014). A Primer On Partial Least Squares Structure Equation Modeling (PLS-SEM). Sage Publications Inc.

Hashjin, S. T., VakilaRoaia, Y., \& Hemati, M. (2014). The Study of Factors Influencing the Accepting of Internet Banking (Case Study: Bank Sepahin Alborz Province ). Arabian Journal of Business and Management Review (OMAN Chapter), 3(7), 85-98.

Hassali, M. A., Khan, T. M., Shafie, A. A., \& Nazir, M. (2009). Public Knowledge About Herbal Beverages in Penang, Malaysia. Australasian Medical Journal, 1(6), 1-11.

Hassan, S. H. (2011a). Consumption of functional food model for Malay Muslims in Malaysia. Journal of Islamic Marketing, 2(2), 104-124. doi:10.1108/17590831111139839

Hassan, S. H. (2011b). Managing conflicting values in functional food consumption: the Malaysian experience. British Food Journal, 113(8), 1045-1059. doi:10.1108/00070701111153788 
Ibrahim, H., \& Najjar, F. (2008). Assessing The Effects of Self-Congruity, Attitudes and Customer Satisfaction on Customer Behavioural Intentions in Retail Environment. Marketing Intelligence \& Planning, 26(2), 207227. doi:10.1108/02634500810860638

Ismail, S., \& Mohd Mokhtar, S. S. (2015). Moderating Effect of Perceived Risk on the Relationship Between Product Safety and Intention. Management Science Letters, 5, 205-212. doi:10.5267/j.msl.2014.12.016

Jaafar, S. N., Pan, E. L., \& Mohamed@Naba, M. (2012). Customers’ Perceptions, Attitude and Purchase Intention Towards Privete Label Food Products in Malaysia. Asian Journal of Business and Management Sciences, 2(8), 73-90.

Jamal, J. A. (2006). Malay Traditional Medicine An Overview of Scientific and Technological Progress. Tech Monitor, (Nov/Dec), 37-49.

Kelly, J. P., Kaufman, D. W., Kelley, K., Rosenberg, L., Anderson, T. E., \& Mitchell, A. A. (2005). Recent trends in use of herbal and other natural products. Archives of Internal Medicine, 165(3), 281-6. doi:10.1001/archinte.165.3.281

Kim, H. Y., \& Chung, J.-E. (2011). Consumer Purchase Intention For Organic Personal Care Products. Journal of Consumer Marketing, 28(1), 40-47. doi:10.1108/07363761111101930

Klepser, T. B., Doucette, W. R., Horton, M. R., Buys, L. M., Ernst, M. E., Ford, J. K., .. Klepser, M. E. (2000). Assessment of Patients' Perceptions and Beliefs Regarding. Pharmacotherapy, 20(1), 83-87.

Lodorfos, G. N., Mulvana, K. L., \& Temperley, J. (2006). Consumer Behaviour: Experience,Price,Trust and Subjective Norm in OTC Pharmaceutical Market. Special Edition on Customer Satisfaction - Global Perspective, 41-66.

Maldonado, U. P. T., Khan, G. F., Moon, J., \& Rho, J. J. (2011). E-learning Motivation and Educational Portal Acceptance in Developing Countries. Online Information Review, 35(1), 66-85. doi:10.1108/14684521111113597

Marinac, J. S., Buchinger, C. L., Godfrey, L. A., Wooten, J. M., Sun, C., \& Willsie, S. K. (2007). Herbal Products and Dietary Supplements: A Survey of Use, Attitudes, and Knowledge Among Older Adults. World Health, 107(1), 13-23.

Mason, W. A., Conrey, F. R., \& Smith, E. R. (2007). Situating Social Influence Processes: Dynamic, Multidirectional Flows of Influence Within Social Networks. Personality and Social Psychology Review, 11, 279-300. doi:10.1177/1088868307301032

Michaelidou, N., \& Hassan, L. M. (2008). The Role of Health Consciousness , Food Safety Concern and Ethical Identity On Attitudes and Intentions Towards Organic Food. Internal Journal of Consumer Studies, 32, 163170. doi:10.1111/j.1470-6431.2007.00619.x

Mitha, S., Nagarajan, V., Gohar Babar, M., Ahmad Siddiqui, M. J., \& Qasim Jamshed, S. (2013). Reasons of using complementary and alternative medicines ( CAM ) among elderly Malaysians of Kuala Lumpur and Selangor states: An exploratory study. Journal of Young Pharmacists, 5, 50-53. doi:10.1016/j.jyp.2013.05.002

Mohamed Omar, K., Nik Mat, N. K., Ahmed Imhemed, G., \& Mahdi Ahamed Ali, F. (2012). The Direct Effects of Halal Product Actual Purchase Antecedents among the International Muslim Consumers. American Journal of Economics, 2(4), 87-92. doi:10.5923/j.economics.20120001.20

Mohd Zahran, M. Z., Rezai, G., \& Mohamed, Z. (2012). Predicting Consumer Intention to Shop Herbal Products Online: An Empirical Investigation. In 2nd International Conference On Management (2nd ICM 2012) Proceeding (pp. 984-995).

Mukhtar, A., \& Butt, M. M. (2012). Intention to Choose Halal products: The Role of Religiosity. Journal of Islamic Marketing, 3(2), 108-120. doi:10.1108/17590831211232519

Nunnally, J. C. (1978). Psychometric Theory (2nd Editio.). New York: McGraw-Hill.

O'Connor, E. L., \& White, K. M. (2009). Intentions and willingness to use complementary and alternative medicines: what potential patients believe about CAMs. Complementary Therapies in Clinical Practice, 15(3), 136-40. doi:10.1016/j.ctcp.2009.03.003

P.Pomsanam, K.Napompech, \& S.Suwanmaneepong. (2014). An Exploratory Study on the Organic Food Purchase Intention Among Thai-Cambodian Cross-Border Consumers. Asian Journal of Applied Sciences, $1-12$.

Paul, J., \& Rana, J. (2012). Consumer Behavior and Purchase Intention For Organic Food. Journal of Consumer Marketing, 29(6), 412-422. doi:10.1108/07363761211259223

Pawlak, R., Brown, Æ. D., Kay, Æ. M., Connell, C., Yadrick, Æ. K., \& Blackwell, A. (2007). Theory of Planned Behavior and Multivitamin Supplement Use in Caucasian College Females. Journal Primary Prevent, 1-15. doi:10.1007/s10935-007-0112-X 
Pino, G., Peluso, A. M., \& Guido, G. (2012). Determinants of Regular and Occasional Consumers’ Intentions to Buy Organic Food. Journal of Consumer Affairs, 46(1), 157-169. doi:10.1111/j.1745-6606.2012.01223.x

Raghavendra, H., Yogesh, H., Gopalakrishna, B., Chandrashekhar, V., Sathis Kumar, B., \& Kumar, V. (2009). An Overview Of Herbal Medicine. International Journal of Pharmaceutical Sciences, 1(1), 1-20.

Rezai, G., Mohamed, Z., \& Shamsudin, M. N. (2011). Malaysian Consumer's Perceptive Towards Purchasing Organically Produce Vegetable. In 2nd International Conference on Business and Economic Research (2nd ICBER 2011) Proceeding (pp. 1774-1783).

Rezai, G., Teng, P. K., Mohamed, Z., \& Shamsudin, M. N. (2012). Functional Food Knowledge and Perceptions among Young Consumers in Malaysia. World Academy of Science, Engineering and Technology, 63, 307312.

Rezai, G., Zahran, M. Z. M., \& Mohamed, Z. (2013). Factors Influencing Malaysian Consumers Online Purchase of Herbal Products. Pertanika Jounal Social Science \& Human, 21(S), 109-122.

Rimal, A. (2005). Meat Labels: Consumer Attitude and Meat Consumption Pattern. International Journal of Consumer Studies, 29, 47-54.

Rimal, A., Moon, W., \& Balasubramanian, S. K. (2006). Perceived Risks of Agro-Biotechnology and Organic Food Purchases in the United States. Journal of Food Distribution Research.

Ringle, C. M., Wende, S., \& Becker, J.-M. (2015). SmartPLS. Boenningstedt, Germany: SmartPLS GmbH. Retrieved from www.smartpls.com

Saokaew, S., Suwankesawong, W., Permsuwan, U., \& Chaiyakunapruk, N. (2011). Safety of Herbal Products in Thailand An Analysis of Report in the Thai Health Product Vigilance Center Database from 2000 to 2008, 34(4), 339-351.

Shafiq, R., Raza, I., \& Zia-ur-rehman, M. (2011). Analysis of the factors Affecting Customers' Purchase Intention: The Mediating Role of Perceived Value. African Journal of Business Management, 5(26), 1057710585. doi:10.5897/AJBM10.1088

Sok Foon, Y., \& Chan Yin Fah, B. (2011). Internet Banking Adoption in Kuala Lumpur: An Application of UTAUT Model. International Journal of Business and Management, 6(4), 161-167. doi:10.5539/ijbm.v6n4p161

Son, J., Jin, B., \& George, B. (2013). Consumers' Purchase Intention Toward Foreign Brand Goods. Management Decision, 51(2), 434-450. doi:10.1108/00251741311301902

Soyez, K., Francis, J. N. P., \& Smirnova, M. M. (2012). How individual, Product and Situational Determinants Affect The Intention To Buy And Organic Food Buying Behavior: A Cross-National Comparison In Five Nations. International Journal of Marketing, 51(1), 27-35. doi:10.1007/s12642-011-0073-8

Tabachnick, B. G., \& Fidell, L. S. (2007). Using Multivariate Statistics. Boston, MA: Pearson Education Inc.

Tangkiatkumjai, M., Boardman, H., Praditpornsilpa, K., \& Walker, D. M. (2013). Prevalence of herbal and dietary supplement usage in Thai outpatients with chronic kidney disease : a cross-sectional survey. BMC Complementary and Alternative Medicine, 13(153), 1. doi:10.1186/1472-6882-13-153

Tarkiainen, A., \& Sundqvist, S. (2005). Subjective norms, attitudes and intentions of Finnish consumers in buying organic food. British Food Journal, 107(11), 808-822. doi:10.1108/00070700510629760

Thanisorn, R., Byaporn, N., \& Bunchapattanasakda, C. (2012). Thai Consumers ’ Perception on Herbal Cosmetic Products: A Comparative Study of Thai and Imported Products. Information Management and Business Review, 4(1), 35-40.

Thongruang, C. (2008). Consumer Purchasing Behavior for Herbal Medicine in Drugstore in Bangkok. Naresuan University Journal, 16(3), 195-202.

WHO. (2011). The World Medicines Situation 2011. Journal of alternative and complementary medicine (New York, N.Y.) (Vol. 16). doi:10.1089/acm.2009.0657

Zia-ur-Rehman, \& Dost, M. K. (2013). Conceptualizing Green Purchase Intention in Emerging Markets: An Empirical Analysis on Pakistan. In The 2013 WEI International Academic Conference Proceedings (pp. 99120). 